\title{
Appraiser behaviour and appraisal smoothing: some qualitative and quantitative evidence
}

\author{
Paper Presented to the Annual Meeting \\ American Real Estate Society \\ Naples, Florida, April 2002
}

\author{
Andrew Baum, Neil Crosby , Pat McAllister* \\ Dept of Land Management and Development \\ School of Business \\ The University of Reading \\ PO Box 219 \\ Whiteknights \\ Reading \\ RG6 6AW \\ UK

\begin{abstract}
Tel : + 44 (0) 1189316657
Fax : + 44 (0) 1189318172

E.mail : p.m.mcallister@rdg.ac.uk
\end{abstract} \\ Paul Gallimore, Adelaide Gray \\ Dept of Surveying \\ Nottingham Trent University \\ Burton St \\ Nottingham \\ United Kingdom \\ NG1 4BU
}




\begin{abstract}
There is a substantial literature which suggests that appraisals are smoothed and lag the true level of prices. This study combines a qualitative interview survey of the leading fund manager/owners in the UK and their appraisers with a empirical study of the number of appraisals which change each month within the IPD Monthly Index. The paper concentrates on how the appraisal process operates for commercial real estate performance measurement purposes. The survey interviews suggest that periodic appraisal services are consolidating in fewer firms and, within these major firms, appraisers adopt different approaches to changing appraisals on a period by period basis, with some wanting hard transaction evidence while others act on 'softer' signals. The survey also indicates a seasonal effect with greater effort and information being applied to annual and quarterly appraisals than monthly. The analysis of the appraisals within the IPD Monthly Index confirms this effect with around 5\% more appraisals being moved at each quarter day than the other months. More November appraisals change than expected and this suggests that the increased information flows for the December end year appraisals are flowing through into earlier appraisals, especially as client/appraiser draft appraisal meetings for the December appraisals, a regular occurrence in the UK, can occur in November. January illustrates significantly less activity than other months, a seasonal effect after the exertions of the December appraisals.
\end{abstract}

Key words: Appraisal smoothing, appraiser behaviour, real estate index. 


\section{Introduction}

In the absence of continuously traded and securitised markets and the lack of success in developing transaction-based indices, commercial property appraisals perform a vital function in the property market by acting as a surrogate for transaction prices. As with asset prices in the equity and bond markets, property asset appraisals are central to the interrelated processes of performance measurement, acquisition and disposal. However, within both the professional and academic communities, there is considerable scepticism about their ability to fulfil this role in a completely reliable manner. At the micro-level, there is a consensus that individual appraisals are prone to a degree of uncertainty. At the macrolevel, it is clear that few analysts accept that appraisal-based indices reflect the true underlying performance of the property market. It is commonly held that such indices fail to capture the extent of market volatility and tend to lag underlying performance.

As a consequence, issues such as the level and nature of appraisal uncertainty, and the causes and extent of index smoothing have generated a substantial research literature and professional debate. However, many of the issues remain controversial and unresolved. Whilst it is generally acknowledged that the nature of the process and the structure of the property market render appraisals prone to uncertainty, there is a growing recognition that appraiser behaviour and appraiser response to external influences may increase the likelihood of biased figures. Additionally, it is clear there are often complex feedback processes occurring. Appraisals, in turn, influence the behaviour of market important participants such as investors and financiers. To date, the majority of research and commentary has taken little account of the market context in which appraisals are produced and used while seeking to explain observed consequences such as smoothing and lagging.

The remainder of this paper is organised as follows. The first section draws upon a literature review to explore the relationship between the observed characteristics of appraisal-based performance indices and the appraisal process. This is followed by a discussion of the results of interview-based research into the process by and context in which appraisals are formed. In the penultimate section, data from the Investment Property Databank on the levels of appraisal 'stickiness' is analysed. The final section outlines the main conclusions of the research. 


\section{Appraisal formation}

$\alpha$

In the real estate economics literature, the appraisal process is conventionally conceptualised as a procedure through which appraisers rationally process information on comparables to arrive at an estimate of current value. At the same time, it has been recognised that the inevitably retrospective nature of this methodology will tend to produce a moving average measurement (Geltner and Miller, 2001, Clayton et al, 2001). Seminal work by Quan and Quigley (1991) demonstrated that smoothed or lagging appraisals were a rational outcome of a thinly traded market. They defined the optimal current appraisal $\left(\mathrm{V}_{\mathrm{t}}\right)$ as being a function of a weighted average of current estimated market price $\left(\mathrm{MP}_{\mathrm{t}}\right.$-established from comparables) and the previous appraisal $\left(\mathrm{V}_{\mathrm{t}-1}\right)$. A weighting factor $(\alpha)$ is applied to each variable and is a function of longitudinal variance (quantity of market movement from previous appraisal) and cross-sectional variance (quantity of uncertainty about reliability of comparable evidence). This was more formally defined as

$$
V_{t}=\alpha M P_{t}+(1-\alpha) V_{t-1}
$$

Hence, it is demonstrated that at the level of the individual property, the incorporation of information from the previous appraisal will tend to improve the quality of the current appraisal $^{1}$. However, it is also recognised that this conceptualisation of the appraisal process is based on a rather narrow, mechanistic perspective of the appraisal task. For instance, Brown and Matysiak (2000b) argue that the question of whether appraisers act in an optimal manner remains unanswered and that the key probably lies in studies of behaviour rather than economics. Geltner $(1998,23)$ argues that "the most useful way to further our understanding of the appraisal smoothing issue is to pursue empirical analysis of commercial property markets".

There is an institutional background to these issues. Crosby, Lavers and Murdoch (1998) argue that this background to the appraisal process in the UK, where appraisals have been increasingly challenged in the courts since the property market recession in 1990, reinforces the appraisers' reliance on actual comparable transaction information, thereby supporting the Quan and Quigley model. The appraiser's defence often relies on the expert evidence of other professional appraisers. It increases the appraiser's reluctance to move appraisals in the absence of hard transaction evidence, even though transactions may be scarce and out 
of date, unless the other evidence is very compelling. Even then, adjustments will probably be conservative and given the circumstances this is rational behaviour.

There is a considerable body of comment and investigation of the 'smoothing' effects of the use of appraisals in the measurement of property investment performance. Smoothing, in the context of appraisal-based property series, has been assumed to refer to an undermeasurement of 'true' variance. Barkham and Geltner (1994, p92) define smoothing as "bias of time series second moments toward zero". Commonly observed statistical qualities of property return indices are:

- relatively high and persistent levels of serial correlation positively linked to frequency of measurement;

- relatively low levels of standard deviation; and

- non-normality in returns with positive skewness.

As well as under-measuring the extent of market change, it is generally held that appraisalbased series fail to accurately record the timing of market movement. In the price discovery literature, it has been consistently found that market change in securitised property investment provides a leading indicator of market change in unsecuritised markets. However, researchers have been cautious about concluding that there is a structural lead/lag relationship. It has been argued that there are strong grounds for concluding that a significant proportion of any lag is due to delayed recording of market change due to the use of appraisals (McAllister and Tarbert, 1998). In the appraisal accuracy literature, Matysiak and Wang (1995) look at the accuracy of appraisals in different market states and suggest that appraisals are higher (lower) than prices when markets are falling (rising). This is consistent with studies in both the US and Australia (Webb, 1994; Newell and Kishore, 1998).

Given the centrality of appraisals to measurement of the investment performance of commercial property and the level of comment and analysis that their usage has generated, it is perhaps surprising that the process by and context in which appraisals are formed and how they are used has remained relatively under-researched. Although appraiser behaviour

This approach, of course, assumes that a previous appraisal exists and that the appraiser is aware of it. In most periodic appraisals, the appraiser will be aware of the previous appraisals. However, for valuations associated with loans or transactions, this may not be the case 
has been used explicitly to explain these statistical qualities, there has been limited empirical investigation of the appraisal processes that may produce them. Understanding processes is critical from the perspective of attempts to recover the 'true' underlying price series. Previous research suggests a number of appraiser traits which may produce the above

(i) Following Quan and Quigley (1991), given 'noisy' transaction prices, appraisers partially adjust in response to new information. This requires a negative contemporaneous cross-correlation between appraisal error and property true return

(ii) Historic appraisals influence current appraisals through an 'anchoring' bias (see Diaz and Wolverton, 1998 and Clayton et al, 2001).

(iii) Appraisal methodologies and institutional constraints drive appraisers towards requiring market transactions in order to change appraisals and, by definition, such transactions are historic and, consequently, produce a delay in recording market change or lagging. At best, appraisers are slow to include non-transaction based information into appraisals.

(iv) There are minimum thresholds which need to be breached before an appraisal is changed (see Brown and Matysiak, 2000a).

The Quan-Quigley model implies negative contemporaneous cross-correlation between appraisal error and property true return. Hence appraisers 'under-react' to market information. It is recognised that appraisal smoothing is not constant and that the effects of (i) and (ii) will be time varying as the level of confidence in current market data and availability of information fluctuates. However, in certain circumstances there may be a positive contemporaneous cross-correlation between appraisal error and property true return. There has been anecdotal evidence that clients can influence appraisers producing 'ramping' of appraisals. Hence 'under-reaction' and 'over-reaction' by appraisers may occur at the same time with the balance between their effects varying at different appraisal points.

Graff and Webb (1997) identify agency costs as a source of significant serial persistence in the returns of individual properties. They argue that this persistence reflects mis-pricing and mis-appraisal, arising from incentives (bonuses, fee structures) for managers to acquire 
assets and to overbid for rarely available assets. However, since the transaction price provides an "anchor" for subsequent appraisal,

"the appraiser will need overwhelming and incontrovertible evidence that temporary/abnormal economic factors were involved in determining the sale price in order to produce an appraisal valuation that differs in a major way from that price" (Graff and Webb, 1997, p. 21).

Subsequent performance reflects the filtering through of the prior over/underpricing into the appraisal process. Further in periodic performance appraisals, the fund manager is unable to observe the effort that goes into the appraisal service. Any lack of movement in appraisals may partially reflect limited appraiser effort rather than poor information arrival, thin market effects etc.

At the level of individual properties, it is now commonly accepted that appraisals are prone to uncertainty. Whilst acknowledging important methodological limitations, empirical studies tend to confirm this view. However, there has been little empirical investigation of how prices are formed in real estate markets and the role that appraisals may have in the price formation process. In the appraisal accuracy literature, it has been pointed out that appraisal may sometimes be a self-fulfilling prophecy as market participants and intermediaries are influenced by historic appraisals in price determination ${ }^{2}$.

A fundamental problem of the de-smoothing literature has been in judging the extent to which appraisal characteristics reflect the appraisal process rather than the inherent inefficiency in the market. These points are not trivial if we wish to appreciate the characteristics of actual trading prices. Geltner (1998) emphasises the difficulties of estimating true returns and the implied assumptions of 'random walk' behaviour in smoothing correction models. It has been pointed out that appraisal-price anchoring may contribute to a process where actual trading prices actually display low volatility. MacGregor and Schwann (2000, p. 14) identify appraisal-price anchoring as a potential source of inertia arguing that

\footnotetext{
"where purchasers rely on appraisals to inform them about the market value of an asset, appraisal smoothing may result in sluggish price adjustment when market participants rely on appraisals to set their reservation prices"
}

\footnotetext{
2 It is important not too overstate the significance of this phenomenon since, taken to its logical conclu sion, it implies static markets. However, in a market characterised by heterogeneity, thin trading, and poor information; it seems reasonable to postulate that a proportion of prices are biased by historic valuations.
} 
In essence, sticky appraisals may produce sticky prices. If it were correct that appraisals bias prices, it would suggest that price-based indices would display some of the same characteristics as appraisal-based series.

Evidence from the capital markets provides further insights into the causes of low volatility and positive serial correlation. Such characteristics tend to be associated with thinly traded markets. In the secondary share market, where certain shares have low trading volumes due to limited information or high risk, it is well documented that the return series of such thinly traded investments display smoothing characteristics. There are a number of interesting studies of the price behaviour of individual thinly traded stocks. For instance Kemp and Reid (1971) use actual share price movements for UK shares and find that thinly traded shares display non-random price changes. In a further study of UK share prices, Grimes and Benjamin (1975) found that only 30\% of the sample behaved as genuine random walks, with $20 \%$ non-random walks and the remainder classified as inconclusive. The non-random walk results were mainly attributable to small relatively unmarketable stocks whereas the pure random walk results were generated from the share price series of large, well-traded companies.

Moreover, recent research suggests that it is possible that the return series of the majority individual components of an aggregate return series may follow a random walk whilst displaying high levels of serial correlation. A recent study by Huber (1997) suggests that thinness of markets contributes to rejection of the random walk hypothesis and also that the use of index data can cause rejection due to "contamination" by less frequently traded shares. This idea has also been explored by Brown and Matysiak (2000a). They argue that smoothing arises from a proportion of appraisals which display "sticky prices" (nominal price rigidities). Individual appraisals may be mainly random walks but a small proportion of sticky appraisals can cause the aggregated index to contain substantial serial correlation. Brown and Matysiak use an economic framework developed by Holbrook Working (1960) and demonstrate that the observed auto-correlation levels in property indices can arise from a "relatively small" number of sticky appraisals over time. However, they adapt the Working (1960) approach to estimate that the observed levels of serial correlation in the IPD Monthly index. Their results imply that $85 \%$ of appraisals are 'sticky' at a given measurement point in this monthly index.

A further possible explanation is that observed auto-correlation in the index can arise from serial cross correlation which can be interpreted to mean that although prices may move individually in a random walk fashion, as a group all prices move in the same general 
direction. In simple terms, the individual appraisals are incorporating information efficiently, but because the market is incorporating information which is moving the market in a similar direction, individual appraisals are related to each other cross-sectionally. Thus, when these are added up in combination in the total returns series, this aggregates to appear as if high temporal auto-correlation is present. Therefore, the auto-correlation is not coming from temporal appraisal smoothing at the individual property level, but rather from lagged aggregate cross-sectional effects.

In summary, it is clear from the above discussion that appraisal-based performance series display the main characteristic associated with thinly traded markets - significant positive serial correlation. It is equally clear that principal-agent problems inherent in the appraisal process have implications for appraisal behaviour. The conjecture that the consequences for information arrival of thin trading are exacerbated by the behaviour of appraisers (and the institutional constraints influencing this behaviour) forms the context for the results of the investigation described below.

This research set out to explore the appraisal formation process and the relationship between appraisals and prices and to examine the assortment of motivations, pressures and constraints shaping appraisal formation.

\section{The Interview Survey and Results}

\section{The survey and interviewees}

In order to investigate the way in which appraisals are formed in the UK, a set of semi structured interview surveys were carried out. The main motivation for a qualitative research approach was that it permitted a more creative, exploratory and flexible style of research given that the initial research agenda was relatively broadly based. The approach is also based on a preconception that detailed knowledge of the research questions is situated with professionals and could be best accessed by personal interview or 'close dialogue' (Clark, 1998). However, it seems apposite to acknowledge the common criticisms of qualitative methodologies so that the key issue of validity is continually considered.

There are risks inherent to a qualitative, interview-based, research methodologies which can lead to doubts about the rigour of the process and the validity of the results and conclusions. There has been considerable debate in the geography literature about approaches to qualitative research practices. Criticisms have been raised concerning the lack of methodological rigour and transparency of qualitative research in social geography in terms 
of the lack of explicit consideration of methodological issues in conducting the research and analysing the data (Baxter and Eyles, 1997). The range of remedies for such limitations has been summarised as 'grounded theory'. In practical terms, the application of such theory focuses on increasing transparency about the research process, researcher reflexivity and data scepticism whilst applying more rigorous methods to the evaluation of data eg. triangulation. Such methods have been applied in this study mainly by using multiple interviewers and by examining the research questions from the perspective of both 'consumers' and 'producers'.

The first set of interviews were with leading property owning and fund management organisations in order to investigate their use of appraisals in property investment decisions. In order to reduce potential interviewer bias, one of the research team was present at all the interviews to ensure that a generally consistent line of investigation was followed. Where earlier interviews had raised interesting issues not previously considered by the research team, later interviews tended to be adapted to include a discussion of these matters. The interview schedules used for the fund manager and appraisers were different but both consisted of a number of factual, closed-end and attitudinal open-ended questions. In total, 20 interviews of fund managers were carried out during May and June, 1999. The size of sample reflected the relatively consolidated nature of the UK institutional property investment market and an intuitive guess at a figure that would be adequate. No formal methodology was developed to identify potential interviewees. The person typically targeted was the senior fund manager or equivalent. The sample can be characterised as selfselecting and 'convenient' in that interviewees were identified from the researchers' knowledge and experience (often personal) of important market participants in terms of organisation and their key personnel. As a result interviews were sometimes between researchers and interviewees who had a pre-existing professional and friendly relationship ${ }^{3}$.

The second set of interviews was carried out with representatives of the leading appraisal firms who were 'producers' of the appraisal services for fund management organisations. It was envisaged that interviewing the 'producers' would provide a fuller picture of the issues addressed as well as providing a check on the reliability and integrity of the data obtained from the fund managers. However, the interview schedule had been refined in light of the findings of the previous set of interviews. In total 11 interviews of heads of appraisal departments were carried out during June and July, 2000. The sample was smaller reflecting

\footnotetext{
3 We have no reason to believe that this biased the data. Given the sensitivity of the subject matter where client influence issues were also explored, this helped openness and in our opinion enhanced the information base. We have observed no differences in response but where existing relationships existed, there does appear to be more information given.
} 
revised perceptions of adequacy and the dominance of the sector by a small number of major providers. This is reflected in the fact that the vast majority of the Investment Property Databank Monthly Index is valued by very few firms, with over $60 \%$ by just three firms, see Table 1. 
Table 1 : Proportion of IPD Monthly Valued by Largest 6 Firms - April 2001.

\begin{tabular}{|l|c|c|}
\hline Valuation Firm & Capital value (£ million) & $\begin{array}{c}\text { Percentage of Monthly } \\
\text { Index }\end{array}$ \\
\hline $\mathbf{1}$ & 2950.3 & 24.4 \\
\hline $\mathbf{2}$ & 2433.7 & 20.1 \\
\hline $\mathbf{3}$ & 2301.4 & 19.1 \\
\hline $\mathbf{4}$ & 1014.8 & 8.4 \\
\hline $\mathbf{5}$ & 943.8 & 7.8 \\
\hline $\mathbf{6}$ & 484.8 & 4.0 \\
\hline Top Six Firms & 10128.8 & 83.9 \\
\hline Total of All Firms & 12078.9 & 100.0 \\
\hline
\end{tabular}

Source : Investment Property Databank

The annual index is not quite so dominated by the hrger firms but the top five still value 64.7\% (Carsberg, 2002). The 11 appraisers interviewed included 5 of the top six listed in Table 1 and a number of smaller firms undertaking the fund appraisals for only 2/3 funds. The 19 owner/manager organisations interviewed who answered the question on value and number of properties, held over 10,000 properties in their portfolios with a value of over $£ 40$ billion, which is just under half of the value of the IPD at that time. But there is diversity between the interviewees in terms of fund size and value, allocation to property and type of organisation. The property companies had a $100 \%$ allocation to property while the funs had between $2 \%$ and $8 \%$. The split by property type was nearly $50 \%$ retail, $30 \%$ offices and $20 \%$ industrial but the range of allocations was between $95 \%$ and $10 \%$ for retail (standard deviation 16\%), 65\% and 3\% for industrials (SD 13\%) and $45 \%$ and $3 \%$ for offices (SD 10\%). The average size of property funds managed by organisations was $£ 2.12$ billion but this ranged from one fund of $£ 10$ billion to a fund of $£ 360$ million (SD $£ 2.45$ billion). Some respondents found the question too general since they were involved in managing a number of funds; each with different weightings.

\section{The survey results}

Reported below are the results of the research in terms of the main issues that emerged from the interviews ${ }^{4}$. The main issues can be categorised into two parts of the fund management process where appraisals have a role; purchase/sale and periodic performance

\footnotetext{
4 In discussing these issues, quotations from interviewees have been used. However, the research interviews were not taped due to the sensitivity of the subject matter. The quotations are therefore transcribed from notes taken by one member of the team, who did not take an active part in the questioning. The quotations are of the main thrust of the point rather than the precise words in some cases.
} 
measurement/financial statement. Appraisals as security for loans are outside of the scope of this research.

\section{The use of appraisals in the transaction process}

Estimates of market (exchange) values and investment (intrinsic) values would be expected to be used in the transacting process as they would be in other markets. In the UK, the distinction between appraisals to identify market value and appraisals to identify the investment values is fully documented in both the academic and professional literature; indeed it is formally institutionalised by definitions of both Market Value and Calculation of Worth appearing in the UK mandatory appraisal manual (RICS, 1995). The owner/manager interviewees virtually all suggested that they carry out estimates of investment value for any property to be sold or purchased and any mismatch with market value may be used to influence buy/sell decisions.

When purchasing, funds usually obtain a purchase report which includes a market appraisal. Controversially, this report is often obtained from the firm introducing the property, whose fee is dependent upon the transaction taking place. The fund manager also normally takes advice from the portfolio appraiser who will be undertaking the periodic performance measurement appraisal. It is possible that the portfolio appraiser also works in the same firm as the introducing agent. Setting aside the conflict of interest and moral hazard issues which arise from this situation, which will be the subject of another paper, the purchaser normally has access to three appraisals, an internal assessment of investment, a purchase report which includes a market value and an opinion from the portfolio appraiser of whether the proposed purchase price will be supported at the next re-appraisal ${ }^{5}$.

"An informal valuation is usually acquired for advice purposes prior to negotiation. This is particularly important for funds who don't want the property to be written down so they take a performance hit"

Despite previous anecdotal practitioner comment that a market value from the portfolio appraiser which did not confirm the purchase price was instrumental in stopping transactions taking place, the research found that very few fund managers felt so constrained. They were confident that their appraisal of investment value would prove correct, that the price levels in the sub-market would adjust to the mismatch that they had isolated and that the appraisers would probably change their mind anyway given the importance of transaction evidence to market appraisals. The appraiser interviews confirmed many previous findings that the UK

The appraisal from the portfolio appraiser may be restricted in that it is a 'desk-top' appraisal undertaken using information supplied by the client. This may raise questions of liability and this issue of status is the subject of an on-going funded research project. 
market appraisal process is still dominated by capitalisation rate comparables rather than any explicit DCF methodology. Purchasers are therefore driven by estimates of investment value rather than market value.

Typical quotes were:

"The company will buy property at a price above independent valuation even for unit linked funds."

"There has never been a problem taking a performance hit as deals are made with an horizon of 3-5 years."

But not all funds are immune.

"The trustees like the price to be underwritten and presentation to the board would not be given without this."

The attitudes of funds when selling are markedly different. Market appraisals played a much more significant role in determining asking prices and therefore affect which properties were eventually sold. Every fund has the last periodic market appraisal 'in the books' and selling below this figure is often difficult. There were basically two types of investor attitude towards an appraisal/price mismatch - 'appraisal-constrained' investors and 'appraisalindependent' investors. For a small majority of fund managers interviewed, a market price below a prior appraisal indicated a 'low' price at which they could not trade. Often a threshold was present at which non-trading would occur, typically if the price diverged from the prior appraisal by more that $5 \%$. The main reasons that selling at a price below latest appraisal was problematic related to obtaining necessary authorisation from trustees and other executive bodies. It was also stated that such a situation could potentially undermine confidence in periodic performance measures based on appraisals of the remainder of the portfolio.

Actual quotes were:

"To sell 3-5\% below the valuation is ok. It is rare to sell any more below"

"Worth is the true indicator of whether a sale should go ahead, not valuation. However, it is uncomfortable to go below valuation"

"As this fund is successful it doesn't matter if it takes a hit on acquisition or sale. However, it is difficult to sell below 5-10\% of the valuation." 
"If valuation is not a reflection of current price then it can be difficult to sell"

"If the sale price is lower than $10 \%$ below valuation it throws into question the valuation of all other assets. It is a psychological barrier"

"If the worth and valuation calculations don't agree then this might cause problems"

However, for others investors, essentially the problem was perceived as a 'high' appraisal. As a result a mismatch between the price and appraisal would not result in an aborted transaction.

\section{"There is no problem selling below book value" \\ "There is no difficulty in selling below valuation" \\ "The valuer may influence but would not stop the deal. Renegotiations of the deal and with the valuer may occur" \\ "The company will sell below valuation with no problem" \\ "If the sale is going to be below valuation it will be examined closely as it will mean a performance hit but if that property is going to drag your performance down anyway then it is worth selling"}

Interviews with appraisers generally confirmed the importance of prior periodic appraisals in the disposal process. It was stated on a number of occasions that sales were more likely to be affected by failure to match a previous performance appraisal. Confirming the findings with the fund managers, a significant proportion of vendors feel unable to sell below 'book value $^{6}$. These findings support the Schwann-MacGregor argument that trading prices are biased by previous appraisals and consequently, may have the same time series qualities as appraisal series.

This finding has important implications for research issues other than the way in which appraisals and prices are formed. First, the need to match previous appraisal on sale within some funds opens up client influence issues. A fund manager may be tempted to try and get the appraisal down so that any subsequent transaction can be negotiated off a lower base. If trustees do not like selling at below appraisal they may be equally pleased to sell above appraisal, to the benefit of trustee/manager relations. Second, the validity of appraisal accuracy studies which compare sales with previous transactions is brought into question.

6 In this context, book value refers to the most recent performance appraisal. 
This research implies that the samples used are biased towards situations where the prices achieved exceeded previous appraisal. Interpretations of the accuracy data need re-visiting in the light of these findings. Both these issues are being developed in other papers. Further, it raises fundamental questions about the attraction of transaction-based indices. The findings suggest that transaction prices reflect a biased sample of transaction prices. This occurs for two reasons. Firstly, as noted above, prices are contaminated by appraisals. Secondly, and more importantly, there is selection bias problem since this evidence implies that transaction prices below prior appraisals would be systematically under-represented ${ }^{7}$.

\section{The periodic appraisal process}

In terms of process, the main issue addressed was standard practice in terms of information research, timing and client consultation.

In terms of levels of effort and research it was clear that levels of research varied with time period. The research did not investigate the contracts between appraiser and client so cannot comment fully on how much these differences were part of the contract or related to different firms' standard practice. But the appraisers did differ in the level of input into the appraisal process. While most suggested that the annual appraisal was very fully researched, the input into monthly and quarterly appraisals was more variable. For example, some of the larger firms suggested that information on rental values and yields was updated every month while others suggested this process only occurred every three months. The comments below give the range of input and the variation between firms.

\section{"The six monthly valuation is a review" \\ "Every quarter the properties are marked to market yield with the advice of an investment colleague...A full ring round for comparables is done every quarter"}

"Monthly meetings are held with the investment team to discuss, sentiment, yields and rentals"

For monthly valuations "they will not run the numbers on every property...For quarterly valuations the valuer will do more"

"Each property is thought about...Monthlys are incredibly difficult to do"

\footnotetext{
${ }^{7}$ This may well explain why unpublished research by IPD in the UK using actual transaction prices to produce an investment performance index display higher levels of serial correlation that appraisal-based indices
} 
"When producing monthly valuations, it is generally a waste of time to look at rental values. This is done every three months...the investment market is considered in detail every three months"

Most appraiser respondents ${ }^{8}$ expressed scepticism of the utility of monthly appraisals given limited information flows in the property market. There is pressure within the UK investment community to move to quarterly appraisals for the whole of the Investment Property Databank universe and there is little doubt that the major firms are already undertaking a major audit of market information every quarter at present. Monthly appraisals are not subject to this level of research and a complete re-running of the information through appraisal computer systems is not carried out.

Another aspect of the provision of appraisals is the change in the market structure of appraisal providers. Table 1 illustrated that the monthly appraisals are predominantly in the hands of very few firms. The interviewees all confirmed that this trend towards concentration was continuing fuelled by the squeeze on fees. A number of smaller appraisal firms were disengaging from appraisals to concentrate on providing other more profitable services to clients. The move towards independent appraisers combined with continuing fee level competition could see the top three firms uilising economies of scale to dominate periodic appraisal provision. There are a number of implications of this, not least that the indices will come to be dominated by the opinions of a few very influential appraisers. The way in which these appraisers approach appraisals and how they interact with clients will influence the shape of performance.

Client/appraiser consultation is very full in the UK market and it is common practice, similar to the findings of Schuck and Levy (1999) in New Zealand, to have a draft appraisal meeting between the client and the appraiser for virtually all appraisals regardless of whether annual, quarterly or monthly. These meetings enable the appraiser to present their suggested appraisals and the client to inform the appraisal with additional information from their more detailed knowledge of the property. The client influence implications of these meetings are investigated elsewhere but there is a general view from both sets of respondents that, despite the concerns, draft appraisal meetings enhance the appraisal process through better information flows.

The timing of the draft meeting was in the month before the appraisal date for monthly/quarterly appraisals but for annual appraisals in often took place earlier, in

8 A single contrary view that the monthly appraisal was just as accurate as the annual was expressed. 
November/early December for the December year end. Typically, most draft appraisal meetings with the client took place in early December with some clients requesting figures as early as October. The November monthly appraisal may be subject to a greater level of consultation and information than other monthly appraisals while December has the greatest level of effort expended.

As indicated earlier, it was clear from discussions that the use of a traditional comparative investment method of appraisal was almost universal. Where there was a perceived lack of 'hard' transaction information in the property market, an interesting and clear difference of opinion among appraisers regarding the information required to change appraisals emerged. In effect, some respondents felt that they could not move their appraisals without transaction evidence, whilst others felt that changes in market sentiment should be reflected. However, the latter also pointed out the difficulties of estimating the timing and level of basically subjective adjustments.

"Transactions that fall through are not market movement. If there is no evidence of a falling market you cannot mark down values. You cannot reflect movement in other markets"

"Monthly valuations ultimately have to move but generally stay stable through lack of volume of evidence"

"Monthly valuations involve picking up the local market information and then tweaking the valuations"

"Often values do not drop in the month that reflects the drop. The change crystallises in the month that it was not necessarily initiated in"

Valuations will move to wider market movement, not necessarily only provable movement. The valuers listen to their investment colleagues"

"Monthly valuations often miss sentiment cues"

For monthly valuations, sentiment builds up over two to three months and then is crystallised in the market. The question rests on where you start reflecting sentiment rather than reality?"

"I am known as a volatile valuer...I do not wait for cast iron evidence"

An interesting and illuminating case study raised initially by interviewees and (then in subsequent interviews by) interviewers was the implications of thin trading for property appraisers in 'stalled' markets. This was apparent in the aftermath of the Russian debt crisis 
of 1998. During October-December of that year, uncertainty about the prospects for the global economy and the property market led to changes in investor sentiment towards commercial property. This was manifested in a decline in transactions due to changing expectations, a lack of buyers and a number of aborted transactions. Many respondents believed that there had been a definite decline in values which, in the absence of adequate trading volume, could not be proven by actual transaction evidence. In terms of the response of fund appraisers, reactions were mixed; some stated that they adjusted appraisals after a delay, whilst others tended to 'sit it out' and wait until evidence appeared. In the event, around $80 \%$ of IPD monthly appraisals remained unchanged in October 1998 and the capital growth index fell by $-0.27 \%$. On average $69 \%$ of appraisals remain unchanged each month and the average capital value change is $0.68 \%$ ignoring whether it is up or down. In November, around $70 \%$ remained unchanged, but $20 \%$ of the $30 \%$ which moved went down. This appears to suggest that the appraisals froze for the first month and were then reduced a month later.

This matches with the evidence from discussions with appraisers. It suggests that they follow a number of strategies when faced with a lack of data supporting market change.

- No adjustment.

- Delayed adjustment.

- Conservative adjustment.

Moreover, a number of appraisers pointed out (without a specific question) that their clients preferred a slow adjustment in appraisals and were wary of volatility. Some respondents suggested that in declining markets, some fund managers wished the decline in values be 'managed' rather than taking place in the period that it occurred. The potential of anchoring to exacerbate these effects was also established. It was confirmed that the same appraiser normally valued the portfolio and was (obviously) aware of previous appraisals. Interestingly, two respondents stated that, in order to reduce the inevitable repetitiveness associated with the appraisal of a single portfolio, they had experimented with revolving the portfolios between different internal individual appraisers. However, the experiment was not sustained due to the subsequent increased volatility that resulted.

It is stressed that these observations are not universal amongst either appraisers or fund managers. However, they do seem to reflect the behaviour of some fund managers and appraisers in specific market circumstances. In falling markets, in particular, lack of transaction evidence reduces information flows. However, the appraisers are selective in 
their information choice. Evidence of changing sentiment and the performance of the public markets seem to be filtered out of the appraisal process. However, this problem is almost certainly exacerbated by the behaviour of a proportion of fund managers who have incentives to influence their appraisers. As indicated earlier, these issues are developed elsewhere.

\section{Appraisal Movements in the IPD Monthly Index}

The discussion in the previous section leads to a number of observations about how frequently undertaken performance measurement appraisals may behave. As indicated previously, there is a well-developed literature on the appraisal process, in particular the approach of appraisers adopting comparable sales techniques for periodic appraisals. Quan and Quigley $(1989,1991)$ demonstrate that an optimal strategy for the appraiser is to determine the weighted average of the previous appraisal and new transaction information. The qualitative research discussed above suggests that the appraisal formation process is more complex with the timing of the appraisal, the terms of the appraisal 'contract' and the traits of the particular client and appraiser influencing appraisal outcomes. Indeed, it has been noted that Brown and Matysiak use backward iteration to predict very high proportions of 'sticky' appraisals in monthly indices.

The level of anchoring would be a function of the arrival of new information. However, it was clear from the interviews that the appraisers did not spread their 'search' for information equally. A number of appraisers indicated that they carried out more market analysis for the quarter day appraisals of March, June, September and December than at the other months, so less anchoring may be expected at each quarter day. However, there is also evidence of some structural inertia in the process. In the UK it is normal practice is for purchaser's costs to be deducted from a 'gross of transaction costs' appraisal. One of the costs is transfer tax (known as Stamp Duty in the UK). After a long period of stability, Stamp Duty rose three times following a change of government in the UK; March 1999 and 1998 and July 1997. All (most) appraisals would be expected to change if the deduction was increased in those months.

In order to identify whether any of these effects are observable, the IPD Monthly index from January 1987 to April 2001 was examined for the number of appraisals which remain unchanged each month. Figure 2 illustrates that on average the proportion of appraisals that remain unchanged month to month over the whole term of the index averages $69 \%$. This is consistent with the prediction of Brown and Matysiak. Figure 2 illustrates how this varies with the (absolute) level of market movement. Not unexpectedly, there is a strong negative 
correlation $(-0.78)$ between the two time series. There are periods when the number of appraisals remaining unchanged was relatively low, most noticeably in the 'hot market' of the late 1980s and in the recovery of 1993/4. However, almost invariably, the majority of appraisals each month remain unchanged throughout the period.

Figure 1 : Absolute capital growth 1986-2001

Figure 2 : IPD Monthly Index - Unchanged Appraisals Jan 1987 to April 2001

\section{Absolute capital growth}

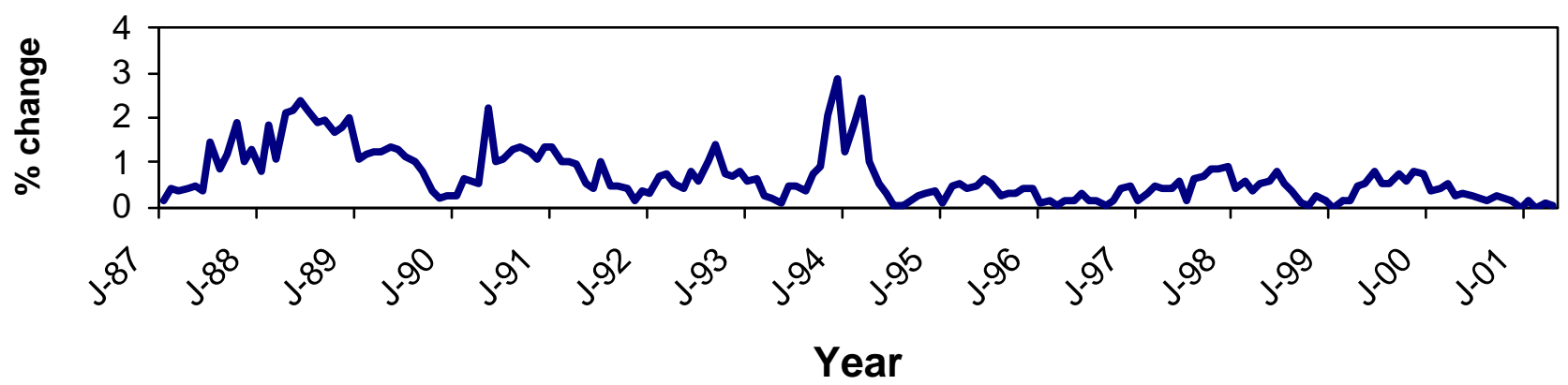

\section{Monthly valuation inertia}

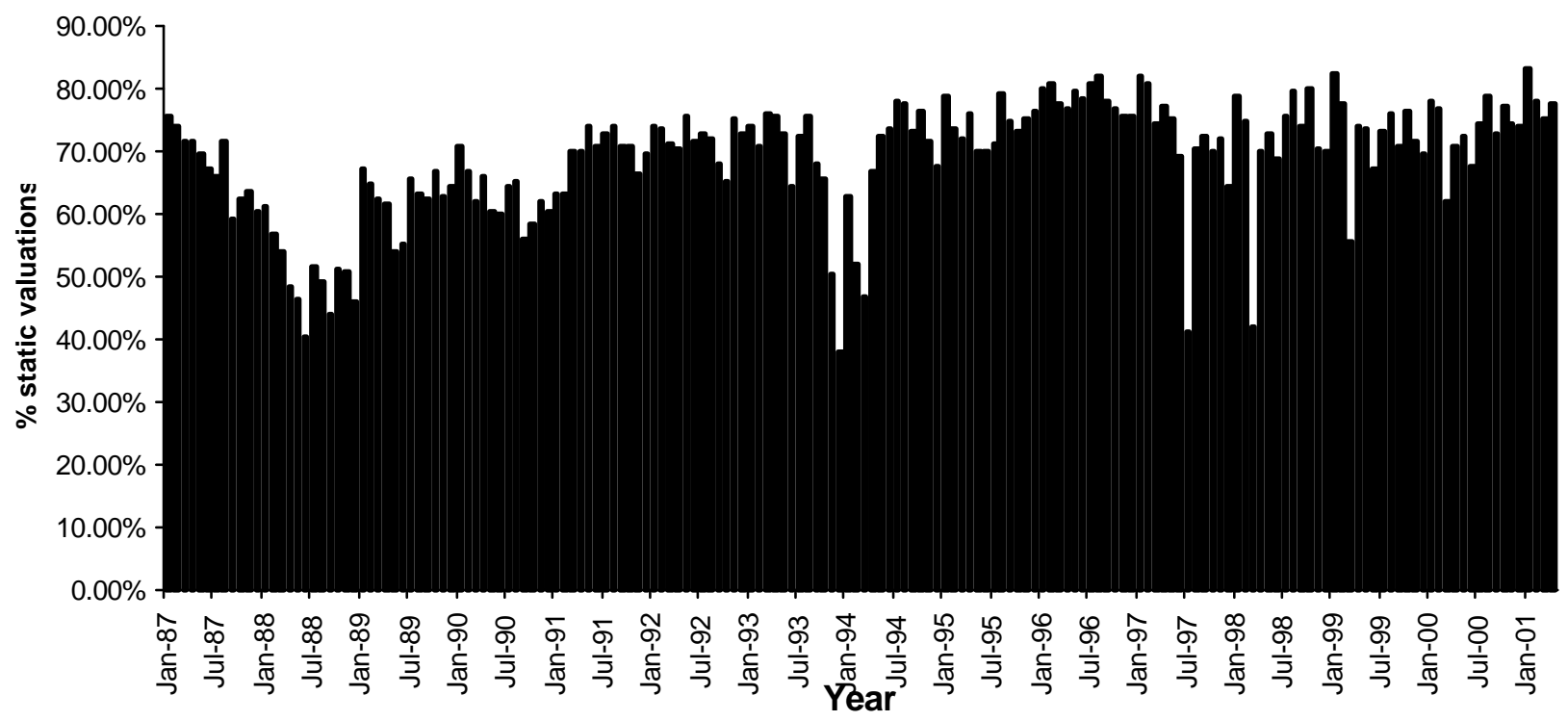

Months when appraisals seemed to move more than others include the three increases in

Stamp Duty. Although more appraisals than usual change at the first appraisal date after a

Stamp Duty increase or decrease is implemented, it is also interesting that a number of appraisals (or appraisers) simply failed to react. 
Table 2 sets out the average number of appraisals that produce an increase in value, a decrease and stay the same in each particular month over the term of the index and they are illustrated in Figure 3. This shows that the months with the greatest change are quarter days. December and March are tied into the annual appraisals of institutional investors (December) and listed property companies (March). November is also a relatively high change month which again fits the hypothesis that appraisals change due to more information being available (or discovered) because of the work being undertaken for the December appraisals. December does not have the greatest number of increased appraisals, this occurs in June with December a close second. March November and December have the highest number of decreasing appraisals; this might be consistent with the influence that potential sales have on year-end appraisals.

Table 2 : Average Change in Monthly Appraisals - IPD Jan 1987 to April 2001

\begin{tabular}{|l|c|c|c|c|c|c|c|c|c|c|c|c|c|}
\hline & Jan & Feb & Mar & Apr & May & Jun & Jul & Aug & Sep & Oct & Nov & Dec & Ave \\
\hline $\begin{array}{l}\text { Average of } \\
\text { \% Same }\end{array}$ & $74.1 \%$ & $70.9 \%$ & $67.3 \%$ & $70.2 \%$ & $69.1 \%$ & $65.9 \%$ & $68.5 \%$ & $72.5 \%$ & $67.4 \%$ & $69.3 \%$ & $67.2 \%$ & $65.0 \%$ & $69.0 \%$ \\
\hline $\begin{array}{l}\text { Average } \\
\text { Increase }\end{array}$ & $15.0 \%$ & $16.8 \%$ & $18.6 \%$ & $17.7 \%$ & $18.9 \%$ & $21.3 \%$ & $17.7 \%$ & $16.4 \%$ & $19.4 \%$ & $17.7 \%$ & $18.8 \%$ & $21.0 \%$ & $18.2 \%$ \\
\hline $\begin{array}{l}\text { Average } \\
\text { \% } \\
\text { Decrease }\end{array}$ & $10.9 \%$ & $12.3 \%$ & $14.1 \%$ & $12.1 \%$ & $12.0 \%$ & $12.8 \%$ & $13.8 \%$ & $11.2 \%$ & $13.2 \%$ & $13.0 \%$ & $14.0 \%$ & $14.0 \%$ & $12.8 \%$ \\
\hline
\end{tabular}

Figure 2 : Average \% of Appraisals Changed in Monthly Appraisals - IPD Jan 1987 to April 2001 


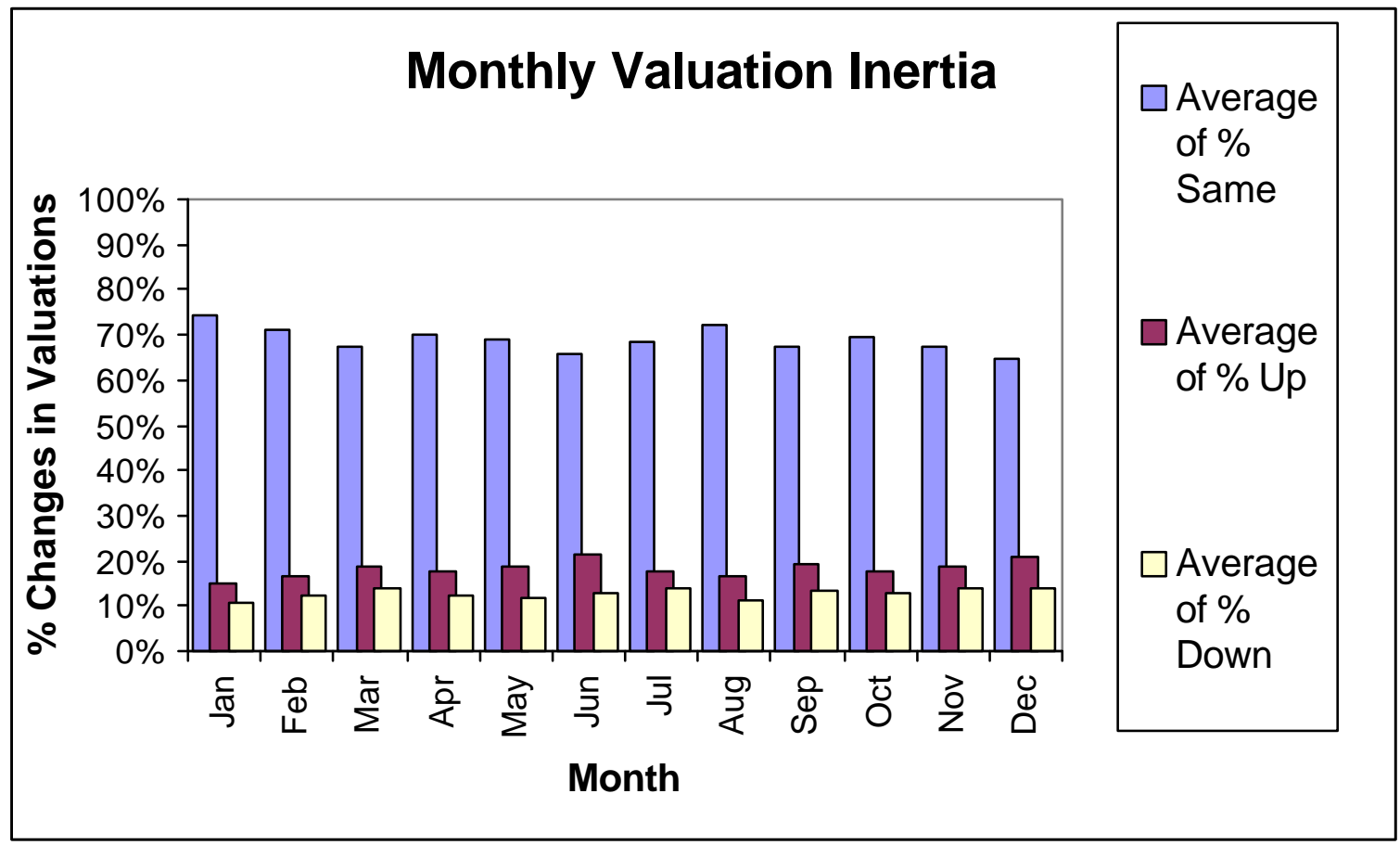

Relative differences are very small and as Figure 2 shows hardly distinguishable. However, Figure 3 does confirm that there is a pattern concerning the movement of appraisals which relates to the annual, half yearly and quarterly appraisals.

Figure 3 : No of Appraisals Changed/Unchanged Compared to Average No. of Appraisals Changed/Unchanged

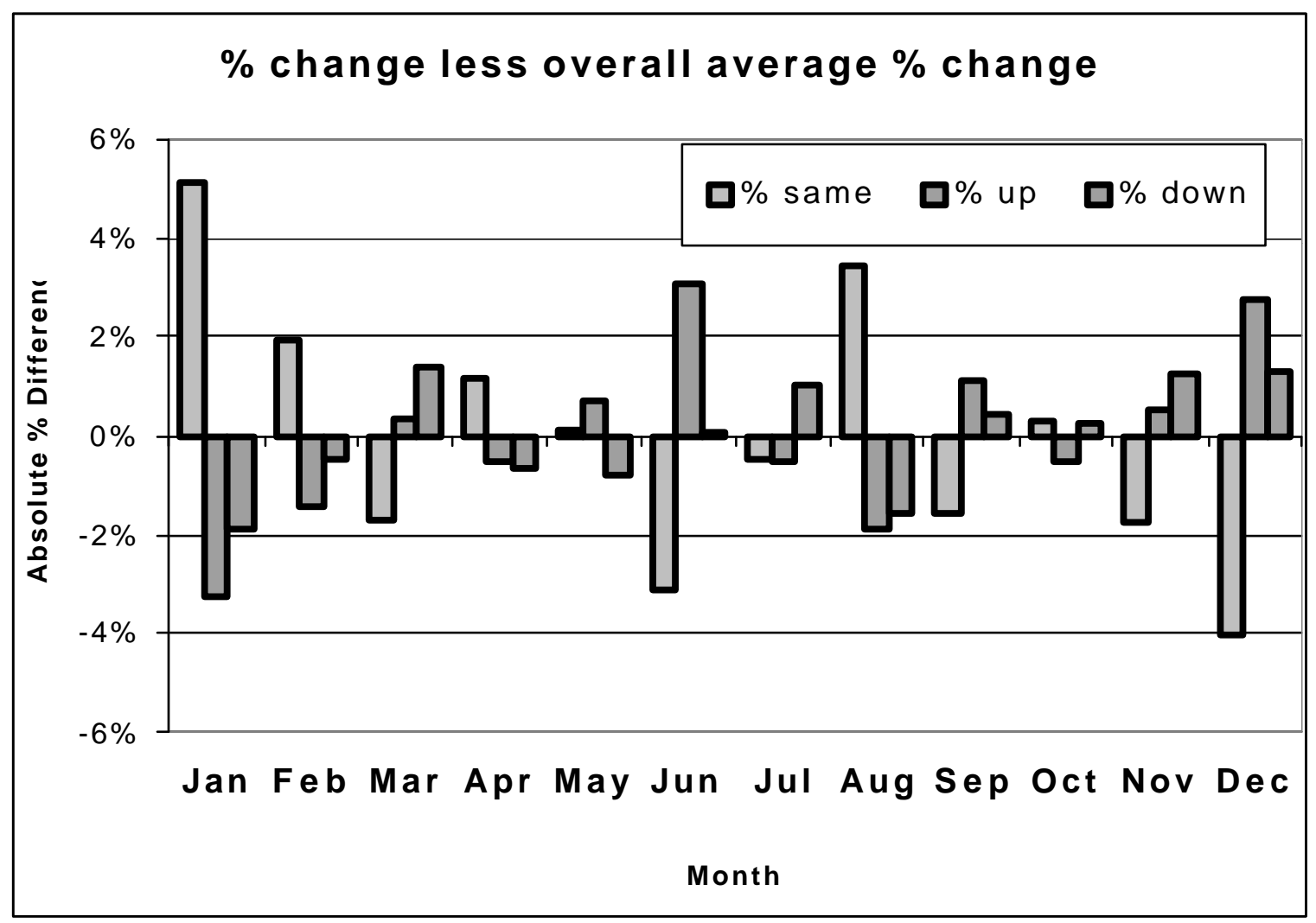


Ignoring any additional issues concerning client influence, the number of appraisals which move could be hypothesised to be based upon what happened in the previous month. The smoothing of the monthly index indicates that the total returns for the month are a function of the returns in the previous month. As total return is a function of the income return plus the capital growth, capital growth would also be expected to be a function of previous month's capital growth. The correlation coefficient for the relationship between capital growth and the previous month's capital growth in the IPD monthly from Feb 1987 to April 2001 is 0.89. As capital growth is a function of the change in appraisals, the amount of appraisal change in a month is likely to be linked to the level of capital growth or fall. Where values are rising steeply, the appraiser will change the appraisals each month, but may implement the change spread over a few months especially if waiting for 'hard' transaction evidence. A high level of change in one month may lead to a high level of change in the next month therefore the number of appraisals which change will be related to the number changed last month and the level of capital gain last month. The level of absolute change in capital gain will be the crucial element, as a high level of change in appraisals will be linked to falling as well as rising markets, with falls introduced incrementally over a few months.

The output of the statistical analysis is set out in Table 3 based upon the hypothesis that the number of appraisals changed will be based upon the number of appraisals changed in the previous month and the absolute level of capital growth in the index in the previous month. In addition the quarter day appraisals appear to have more input in terms of effort and information so these appraisals would be expected to be significant in increasing the number of appraisals changed. The three budget change months may also be a factor so these two elements are introduced as dummy variables. The variables are:

- The level of absolute capital growth (in a rapidly rising or falling market the number of appraisals which are static will fall) in the previous month.

- Whether it is a quarter day (QT dummy).

- The level of static appraisals in the previous month.

- Whether it is a budget month or not? (Budget dummy).

\begin{tabular}{|c|c|c|c|c|c|c|c|}
\hline \multicolumn{2}{|c|}{ Table 3 : Regression Statistics } & \multirow[b]{2}{*}{ ANOVA } & \multirow[b]{3}{*}{$d f$} & \multirow[b]{3}{*}{$S S$} & \multirow[b]{3}{*}{$M S$} & \multirow[b]{3}{*}{$F$} & \multirow[b]{3}{*}{$\begin{array}{c}\text { Significance } \\
F\end{array}$} \\
\hline Multiple R & 0.832 & & & & & & \\
\hline R Square & 0.692 & & & & & & \\
\hline Adjusted R Square & 0.685 & Regression & 4 & 1.0213 & 0.2553 & 93.2322 & 0.0000 \\
\hline Standard Error & 0.052 & Residual & 166 & 0.4546 & 0.0027 & & \\
\hline
\end{tabular}




\begin{tabular}{lcccccc} 
Observations & 171 & Total & 170 & 1.4759 \\
\hline & Coefficients & $\begin{array}{c}\text { Standard } \\
\text { Error }\end{array}$ & t Stat & P-value & $95 \%$ & $95 \%$ \\
\hline Intercept & 0.1242 & 0.0178 & 6.9709 & 0.0000 & 0.0890 & 0.1594 \\
Abs cap growth lagged & 0.0610 & 0.0112 & 5.4229 & 0.0000 & 0.0388 & 0.0832 \\
\% moved lagged & 0.4068 & 0.0706 & 5.7604 & 0.0000 & 0.2674 & 0.5462 \\
QT Dum & 0.0447 & 0.0086 & 5.1723 & 0.0000 & 0.0276 & 0.0617 \\
Budget Dum & 0.2491 & 0.0307 & 8.1171 & 0.0000 & 0.1885 & 0.3097 \\
\hline
\end{tabular}

Table 3 illustrates that all the variables are significant at the $1 \%$ level including the two dummies for the budget day and the quarter day appraisal. The budget day increases the number of appraisals which move by $25 \%$ and upon quarter days around $4.5 \%$ more appraisals move.

The analysis suggests that there is a process effect. The quarter day appraisals have significantly more movement than other months. In addition a number of other months are significant. In Table 4 the QT dummy is removed and each month is included separately. 


\begin{tabular}{|c|c|c|c|c|c|c|c|}
\hline \multicolumn{2}{|c|}{ Table 4 : Regression Statistics } & \multirow[b]{2}{*}{ ANOVA } & \multirow[b]{3}{*}{$d f$} & \multirow[b]{3}{*}{$S S$} & \multirow[b]{3}{*}{$M S$} & \multirow[b]{3}{*}{$F$} & \multirow[b]{3}{*}{ Significance $F$} \\
\hline Multiple R & 0.878 & & & & & & \\
\hline R Square & 0.771 & & & & & & \\
\hline Adjusted R Square & 0.750 & Regression & 14.0000 & 1.1379 & 0.0813 & 37.5093 & 0.0000 \\
\hline Standard Error & 0.047 & Residual & 156.0000 & 0.3380 & 0.0022 & & \\
\hline \multirow[t]{3}{*}{ Observations } & 171 & Total & 170.0000 & 1.4759 & & & \\
\hline & & Standard & & & & & \\
\hline & Coefficient & Error & $t$ Stat & $P$-value & \multicolumn{2}{|c|}{ Lower $95 \%$ Upper $95 \%$} & \\
\hline Intercept & 0.1017 & 0.0189 & 5.3711 & 0.0000 & 0.0643 & 0.1391 & \\
\hline Abs cap growth lagged & 0.0580 & 0.0102 & 5.6887 & 0.0000 & 0.0379 & 0.0782 & \\
\hline$\%$ moved lagged & 0.4817 & 0.0658 & 7.3211 & 0.0000 & 0.3517 & 0.6117 & \\
\hline Budget Dum & 0.2603 & 0.0285 & 9.1304 & 0.0000 & 0.2040 & 0.3166 & \\
\hline Jan & -0.0783 & 0.0193 & -4.0606 & 0.0001 & -0.1165 & -0.0402 & \\
\hline Feb & 0.0441 & 0.0187 & 2.3611 & 0.0195 & 0.0072 & 0.0810 & \\
\hline Mar & 0.0416 & 0.0187 & 2.2297 & 0.0272 & 0.0047 & 0.0785 & \\
\hline Apr & -0.0205 & 0.0188 & -1.0857 & 0.2793 & -0.0577 & 0.0168 & \\
\hline May & 0.0274 & 0.0186 & 1.4696 & 0.1437 & -0.0094 & 0.0641 & \\
\hline Jun & 0.0539 & 0.0186 & 2.8928 & 0.0044 & 0.0171 & 0.0907 & \\
\hline Aug & -0.0209 & 0.0186 & -1.1243 & 0.2626 & -0.0577 & 0.0158 & \\
\hline Sept & 0.0634 & 0.0191 & 3.3201 & 0.0011 & 0.0257 & 0.1011 & \\
\hline Oct & 0.0065 & 0.0190 & 0.3439 & 0.7314 & -0.0310 & 0.0441 & \\
\hline Nov & 0.0490 & 0.0187 & 2.6135 & 0.0098 & 0.0120 & 0.0860 & \\
\hline Dec & 0.0477 & 0.0159 & 3.0077 & 0.0031 & 0.0164 & 0.0790 & \\
\hline
\end{tabular}

In addition to significantly positive coefficients for the quarter day appraisals, November also has a significant positive coefficient. This follows the information flow argument and the finding that the additional effort that goes into end of year appraisals produces additional movement. In addition, the seasonal "holiday" of January has a significantly negative coefficient. The presence of significantly more appraisals moving in February is the most unexpected result. But one of the factors in the model is the level of movement in appraisals in the previous month. The additional movement in February over and above that expected is a product of the lagged relationship with the lack of movement in January. Although a low number of appraisals change in February, the expectation is even less should change given February follows January.

\section{Implications and Conclusions}

This research suggests perceived limitations and characteristics of appraisal-based investment performance indices can be partly attributed to the nature and context of the appraisal process. Given the crucial lack of trading volume, the research suggests that a significant proportion of appraisals remain sticky due to a combination of lack of information arrival, a lack of search for this information and the institutional context of appraisals. 
The research supports the view that the methodological and institutional stress on transaction evidence restricts the ability of appraisals to react to other types of price-sensitive information. This, in turn, affects price determination since it is clear that the price determination process of a significant proportion of investors is influenced by historic appraisals. However, it is important to re-iterate that there are notable variations in the conduct of the 'actors'. For instance, it is clear that a section of appraisers are responsive (to some degree) to price-sensitive issues apart from transaction evidence and a section of investors are relatively unconstrained by historic appraisals.

Given that this variation of approach exists, concentration of appraisals in the hands of fewer appraisers does raise questions and some were addressed by the recent Carsberg Committee report published by the RICS in the UK (Carsberg, 2002). The structure of appraisal providers and the client/appraiser relationship were significant issues according to Carsberg and the RICS has been recommended to start detailed monitoring of the process and the results of performance measurement appraisals.

Work on the effect of market microstructures identifies the potential effect of trading mechanisms on prices and the time series properties of prices. This study of market participant behaviour suggests that, as expected, appraisals and market prices are intertwined. This is not a problem but research which assumes that they are independent of each other is overly simplistic. It is not necessarily the case that transaction prices should exhibit the characteristics of a stochastic process or are similar to the patterns commonly produced by a Stock Exchange trading environment. There are institutional structures linking appraisals to the mechanics of the price formation process. Negotiated transactions rely on appraisals to act as a basis for offers/asking prices and they also act in some type of 'confirmatory' capacity for transaction approval. More importantly, for a significant proportion of investors, historic appraisals often provide a 'floor' below which they cannot sell. Therefore, observed prices are likely to be 'smoothed' to some degree by the same forces as appraisals. Such structural price 'smoothing' is a product of the trading environment.

The empirical study of the IPD monthly index finds that the appraisal process produces variation in the level of appraisals, with annual appraisals being more responsive to change than quarterly appraisals, which in turn are more responsive than monthly appraisals. This is not an unexpected finding. It confirms that the level of information and input varies. However, it does not suggest that the quality of the appraisals reduces as the frequency increases. With the push for quarterly appraisals within the UK investment community and a 
planned implementation within the next few years, the research highlights the trade off between cost, quality and frequency. If investors wish to increase the frequency but also keep costs down, the reaction of the appraisers will be to undertake appraisals on restricted information and input. If the move to quarterly appraisals is to improve property market information, then the objective appears to be put at risk. Quarterly appraisals could be the catalyst for improving appraisal quality but the collection of information and the interpretation of that information have a cost attached.

This paper has looked at the appraisal process issues and has purposefully ignored the relationship between the fund manager/owner and the appraiser. This may impact on the findings as any client influence may change values and influence the number of appraisals that change in the data analysed for this paper. The contrast between appraisal movement in January and December may not be solely due to process and information flows. The client / appraiser relationship is the subject of another paper in course of preparation and therefore the conclusions of this paper may be subject to amendment when that work is completed. 


\section{References}

Baxter, J. and Eyles, J. (1997) Evaluating qualitative research in social geography: establishing rigour in interview analysis Transactions of the Institute of British Geographers, 22(4), 505-525

Barkham, R. J. and Geltner, D. M. (1994) Unsmoothing British valuation-based returns without assuming an efficient market, Journal of Property Research, 11, 81-95.

Barkham, R. J. and Geltner, D. M. (1995) Price discovery in American and British property markets, Real Estate Economics, 23, 21-44.

Brown, G. R. and Matysiak, G. (2000a) Sticky Valuations, Aggregation Effects and Property Indices, Journal of Real Estate Finance and Economics 20 (1), 49-66.

Brown G.R. and Matysiak, G. (2000b) Real Estate Investment, Prentice-Hall, London

Clark, G. L. (1998) Stylized Facts and Close Dialogue: Methodology in Economic Geography Annals of the Association of American Geographers, 88 (1), 73-87.

Clayton, J, Geltner, D and Hamilton, S (2001) Smoothing in Commercial Property Valuations: Evidence from Individual Appraisals, Real Estate Economics, 29 (3), 337 360 .

Geltner, D (1998) Appraisal Smoothing: the Other Side of the Story - A comment, Financial Economics Network, www.ssrn.com Working Paper, Department of Finance.

Geltner, D and Miller, N (2001) Commercial Real Estate Analysis and Investments, South-Western College Publishing Company, Cinncinati

Graff, R. and Webb, J. (1997). Agency Costs and Inefficiency in Commercial Real Estate. Journal of Real Estate Portfolio Management, 3,(1), 19-37.

Kemp, A., and Reid, G. (1971) The Random Walk Hypothesis andthe Recent Behavior of Equity Prices in Britain. Economica, Vol 38.

Kinnard, W. N, Lenk, M. M and Worzala, E. M. (1997). Client pressure in the commercial appraisal industry: how prevalent is it? Journal of Property Valuation and Investment, 15 (3), 233-44.

Lai, T and Wang, K. (1998) Appraisal Smoothing: The Other Side of the Story Real Estate Economics, 26, 511-535.

MacGregor and Schwann (2000) Temporal and spatial variations in market liquidity, appraisal smoothing and price discovery in private and public real estate markets, Paper presented at ERES conference, Bordeaux. 
Matysiak, G and Wang, P (1995), Commercial property prices and valuations: analysing the correspondence, Journal of Property Research, 12, 181-202

McAllister, P. and Tarbert, H. (1998), Price or appraisal discovery? An analysis of lead/lag relationships in the property market, Paper delivered at RICS Cutting Edge conference, de Montfort University.

Newell, G. and Kishore, R. (1998), Are valuations an effective proxy for property sales? The Valuer and Land Economist, Vol. 35 (2), 150-153.

Quan, D and Quigley, J. (1991), Price Formation and the Appraisal Function in Real Estate Markets Journal of Real Estate Finance and Economics, 4, 127-146.

Schuck, E. J. and Levy, D. (1999). The Influence of Clients on Valuations: The Client's Perspective. RICS Cutting Edge Research Conference, Cambridge, England.

Webb, B. (1994), On the reliability of commercial appraisals Real Estate Finance, 11, 62 66

Wolverton, M. L and Gallimore, P. (1999). Client Feedback and the Role of the Appraiser. Journal of Real Estate Research. 18 (3), 415-432.

Working, H. (1960) Note on the correlation of the first differences of averages in a random chain. Econometrica, 28, 916-918. 